\title{
Dehydrodivanillin: Multi-dimensional NMR Spectral Studies, Surface Morphology and Electrical Characteristics of Thin Films
}

\author{
Manoj Gaur, Jaya Lohani, ${ }^{\dagger}$ V. R. Balakrishnan, ${ }^{\dagger}$ P. Raghunathan, ${ }^{\ddagger}$ and S. V. Eswaran ${ }^{-}$ \\ St. Stephen's College, University of Delhi, Delhi-110007, India. "E-mail: sweswaran'agmail.com \\ -Solid State Phwsics Laboratory, Lucknow Road, Delhi-110054, India \\ - National Brain Research Centre, Manesar. 122050. India \\ Received June 3, 2009, Accepted September 9, 2009
}

\begin{abstract}
The complete structural characterization of dehydrodivanillin, an important natural product of interest to the food, cosmetics and aroma industries, has been carried out using multi-dimensional NMR spectroscopic techniques, and its previously reported ${ }^{13} \mathrm{C}-\mathrm{NMR}$ values have been reassigned. Dense and granular thin films of delyydrodivanillin have been grown by sublination under high vacuun and studied using Scanning Electron Microscopy (SEM), electrical and optical techniques. The transmittance spectra of the films indicate a wide optical band gap of more than $3 \mathrm{eV}$. Typical I-V characteristics of Glass/TO/dehydrodivanillin/Al structure exhibited moderate current densities $\sim 10^{+4} \mathrm{~A} / \mathrm{cm}^{2}$ at voltages $>25 \mathrm{~V}$ with an appreciable SCLC mobility of the order of $10^{-6} \mathrm{~cm}^{2} / \mathrm{V}$-s.
\end{abstract}

Key Words: Dehydrodivanillin, 2 D-NMR. J-V Characteristics. SEM, SCLC mobility

\section{Introduction}

Dehydrodivanillin (3.3 $3^{\circ}$-Diformy l-6.6 ${ }^{\circ}$-dihy'droxy -5.5 -dimethoxybiphenyl) (Fig. 1) is a natural product isolated from lignins of several important plant species. ${ }^{1.2}$ It is commercially important in the cosmetics. pharmaceuticals and food stuffs industries ${ }^{3,4}$ as an antioxidant and a flavouring agent. ${ }^{5}$ Moreover. it has been used in the preparation of positive photoresists for microlithography. ${ }^{6.7}$ It has been synthesized by the oxidative coupling of vanillin using soyabean peroxidase. $\mathrm{FeCl}_{3}{ }^{8}$ or sodium/potassium persulfate ${ }^{8}$ as the oxidising agent. Dehydrodivanillin is of interest in the present study because such small organic molecules have gained importance in recent years for electronic device applications e.g. light-emitting diodes (LEDs) and solar cells. Furthermore. amorphous and polycrystalline films of such small organic molecules offer good charge transport and photovoltaic properties. ${ }^{10.11}$ A theoretical study on nonlinear optical properties of the title compound has indicated a $\pi$-electron exchange between the two rings due to conjugation ${ }^{12}$ and this prompted us to carry out measurements of the electrical and optical characteristics and surface morphology of thin films of this compound. A detailed structural characterization of molecular dehydrodivanillin was also done using multi-dimensional NMR methods.

\section{Experimental}

Optical measurements were done on a CARY-5E UV-VisNIR spectrophoto- meter. IR spectnim was recorded on a Spectrum BX series spectrophotometer using $\mathrm{KBr}$. The NMR Spectra were recorded on Bniker $500 \mathrm{MHz}$ instrument. $\mathrm{HMBC}$ and $\mathrm{HMQC}$ were recorded on Bruker $400 \mathrm{MHz}$ instrument. GC-MS studies were carried out using JEOL JMS600 instrument. For device preparation, indium tin oxide (ITO) coated glass substrates were cleaned thoroughly by a sequential orga-

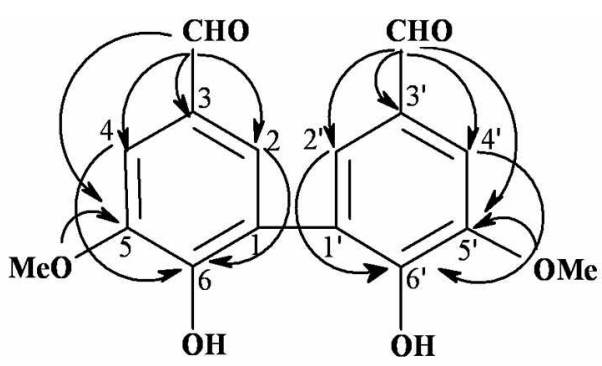

Figure 1. Key HMBC correlations of dehydrodivanillin.

nic wash procedure using acetone and iso-propanol. Devices were patterned using a resist followed by wet chemical etching. A thin film of Dehydrodivanillin ( $300 \mathrm{~nm}$ ) was grown over ITO coated glass in a vacuum coating unit, under a base pressure of $2 \times 10^{-6} \mathrm{mbar}$ at a rate of deposition $<0.5 \mathrm{~A} / \mathrm{s}$. To fonm the metal contacts. aluminum (200 nm) was thermally evaporated, at deposition rate $<1 \mathrm{~A} / \mathrm{s}$. over the film through a shadow mask. The active area of the resulting devices was $0.04 \mathrm{~cm}^{2}$. SEM investigations were carried out on a LEO 1430 instrument. I-V measurements were performed. on samples immediately after deposition of electrodes under normal class 10000 clean room environmental conditions $\left(25^{\circ} \mathrm{C}\right.$ and $\mathrm{RH} \sim 45$ $50 \%$ ). using a Keithley 2410 sourcemeter.

\section{Results and Discussion}

NMR Studies. The expected meta-coupling in the ${ }^{1} \mathrm{H}-\mathrm{NMR}$ spectrum of delyy drodivanillin has not been previously detected. We have observed this $\left(J_{\mathrm{tm}}=3 \mathrm{~Hz}\right)$ using a $500 \mathrm{MHz}$ instnument. ${ }^{13}$ Further. the structural aspects of the molecule have also been investigated using 2D-NMR techniques. Based on results obtained. we conclude that previously the ${ }^{13} \mathrm{C}-\mathrm{NMR}$ values for this structure have been wrongly assigned. ${ }^{14}$ The Nuclear Overhauser spectrum (NOESY, Fig. 2), in addition to self correlations, showed the correlation of aromatic proton 


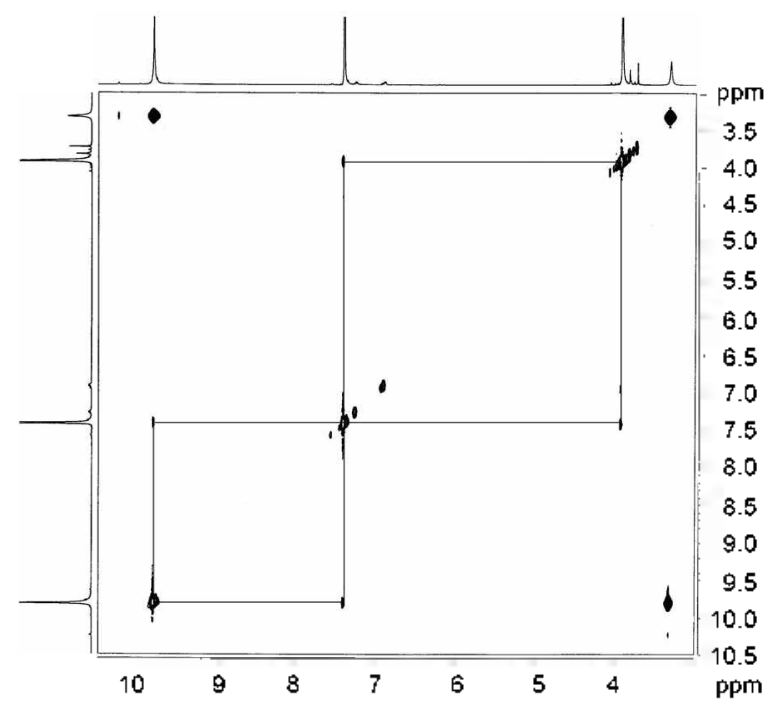

Figure 2. NOESY spectrum of dehydrodivanillin.

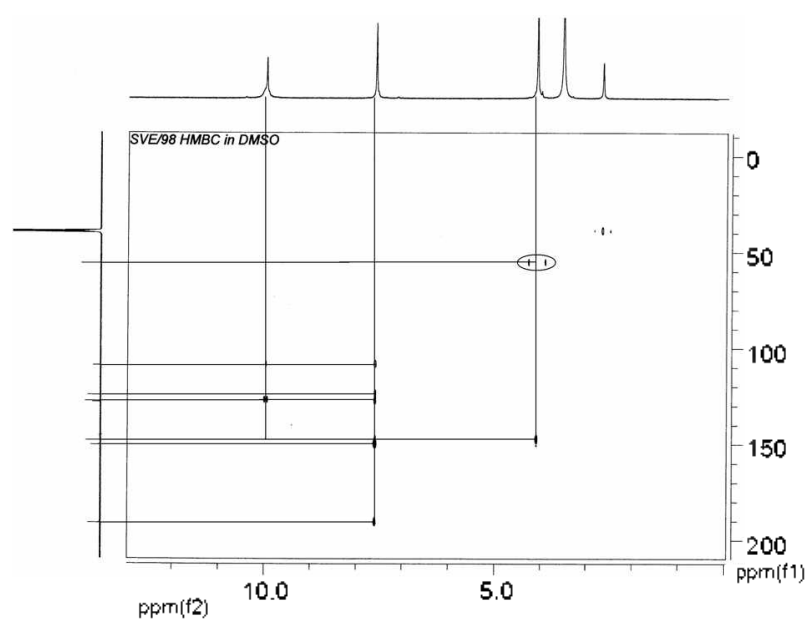

Figure 3. HMBC spectrunn of dehydrodivanillin.

( $\delta 7.4$ ) with the methoxyl protons $(\delta 3.9)$ and the aldehy'de proton at $\delta 9.8$. The spectrum showedthe presence of an aromatic proton ortho to methoxy group at $\mathrm{C}-4$. The aldehyde group correlated with two aromatic protons i.e. at C-2 and C-4. ortho to it. Keycorrelations from the Heteronuclear Multiple Bond

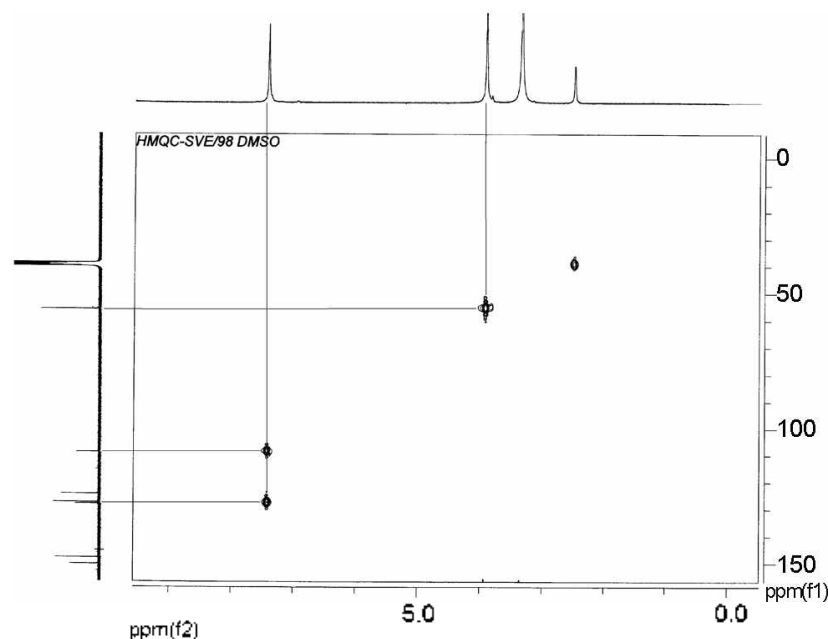

Figure 4. HMQC spectrum of dehydrodivanillin.

Correlation (HMBC) spectrun are shown in Figure 1. The HMBC spectrum (Fig. 3) shows a 3-bond cross peak between the methoxy protons at $\delta 3.9$ and $C-5$ at $148 \mathrm{ppm}$. The two peaks for the methoxy protons. show $n$ in circle. in the HMBC spectrum are the HSQC peaks that were not completely suppressed as they are not correlating with any ${ }^{13} \mathrm{C}$ peaks but instead are bisecting the actual carbon upon which those protons are sitting. A 2-bond cross peak was observed between the aldehyde protons at $\delta 9.8$ and the $\mathrm{C}-3 \& \mathrm{C}-3$ ' carbons at $127.6 \mathrm{ppm}$. with a resolved coupling of $23.4 \mathrm{~Hz}$. The Heteronuclear Multiple Quantum Correlation (HMQC) spectrum (Fig. 4) shows a cross peak between the aromatic protons and the carbons at 109.20 and 127.97 ppm identifying then as either C-2 or C-4. A $3-$ bond coupling of $\sim 6.4 \mathrm{~Hz}$ is resolved in the $\mathrm{HMBC}$ from the protons on $\mathrm{C}-2 / \mathrm{C}-4$ to hydrosyl bearing carbon $\mathrm{C}-6$ at 150.66 ppm and $\mathrm{C}-4$ is assigned as the most shielded aromatic carbon at $109.2 \mathrm{ppm}$. Consequently, the peak at $127.97 \mathrm{ppm}$ has been assigned to $\mathrm{C}-2$. The only remaining unassigned peak in ${ }^{13} \mathrm{C}$ NMR spectrum is a quaternarycarbon at $124.6 \mathrm{ppm}$. which must belong to the $\mathrm{C}-1$ carbons of the biphenyl linkage. The correlations of 2D-NMR have been summarized in Table 1 .

Thin Film Studies. Transnuittance of dehy drodivanillin filnts (over glass) was studied in the range $200-1000 \mathrm{~nm}$. An absorption edge at $360 \mathrm{~nm}$ was obtained which indicated a wide energy band gap of $3.43 \mathrm{eV}$. A typical room temperature current density-voltage (J-V) curve for Glass/ITO/dehỵdrodivanillin/

Table 1. Assignment of 2D-NMR spectra of dehydrodivanillin

\begin{tabular}{|c|c|c|c|c|c|}
\hline Position of $\mathrm{H}$ & ${ }^{1} \mathrm{H}-\mathrm{NMR}(\tilde{\delta})$ & ${ }^{13} \mathrm{C}-\mathrm{NMR}$ (ppmin) & NOESY & HMQC & HMBC \\
\hline $1 / 1^{\circ}$ & & 124.6 & & & \\
\hline $2 / 2^{\prime}$ & 7.4 & 127.9 & $\mathrm{CHO}$ & $C-2$ & $\mathrm{C}-1, \mathrm{C}-3, \mathrm{C}-4, \mathrm{C}-6, \mathrm{CHO}$ \\
\hline $3 / 3$ & & 127.6 & & & \\
\hline $4 / 4$ & 7.4 & 109.2 & $\mathrm{CHO}, \mathrm{OCH}_{3}$ & $C-4$ & $\mathrm{C}-2, \mathrm{C}-3, \mathrm{C}-6, \mathrm{CHO}$ \\
\hline $5 / 5$ & & 148.2 & & & \\
\hline $6 / 6^{\circ}$ & & 1506 & & & \\
\hline $\mathrm{OCH}_{3}$ & 3.9 & 55.9 & & $\mathrm{OCH}_{3}$ & $\mathrm{OCH}_{3}, \mathrm{C}-5$ \\
\hline $\mathrm{CHO}$ & 9.8 & 191 & & & $C-2, C-3, C-4, C-5$ \\
\hline
\end{tabular}




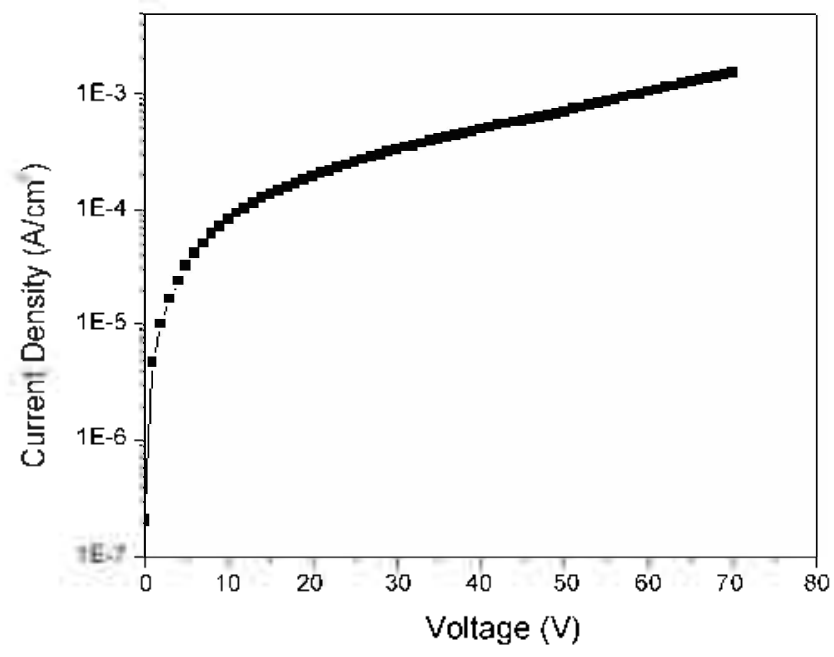

Figure 5. l-V Characteristics of (jlass [TO/dchy drodivanillin/Al thin film electronic devices.

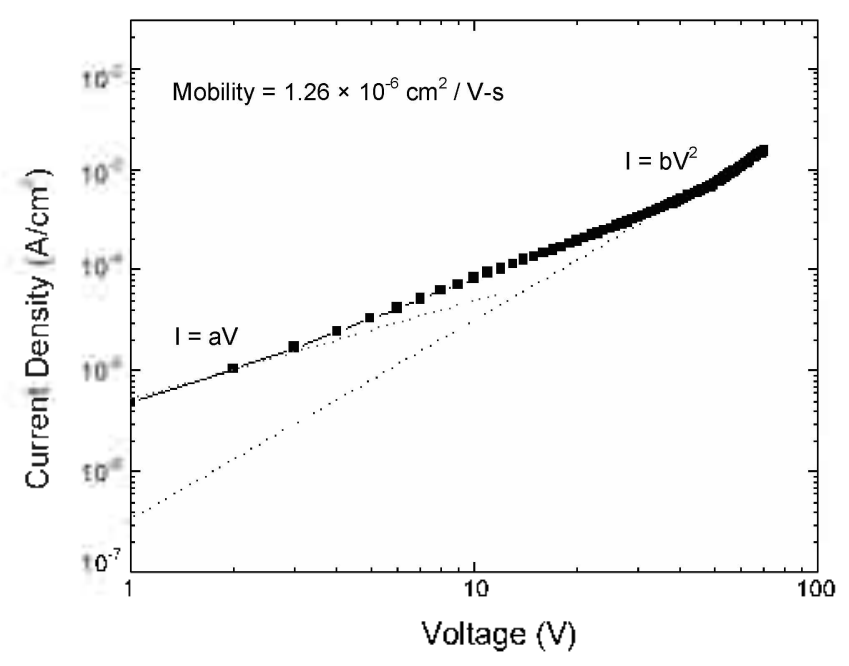

Fighure 6. Mobility measuremenl from SCI.C region.

Al device is shown in Fig. 5. In such devices ITO acts as anode and the hole injecting layer while the aluminum is used as the cathode. The current initially increases sharply in low voltage regime. After that, it increases steadily at a constant rate in the high voltage regine $(>25 \mathrm{~V})$ with moderate current density of the order of $10^{-4} \mathrm{~A} / \mathrm{cm}^{2}$. In general, two separate voltage regions can be distinguished in Fig. 6. The device at low voltage demonstrates nearly ohmic $\mathrm{l}-\mathrm{V}$ dependence. At higher voltage. a distinct region with $\mathrm{I} \propto \mathrm{V}^{2}$ was observed. Standard semiconductor theory predicts this type of $\mathrm{l}-\mathrm{V}$ behaviour in case of space charge limited current (SCLC). Considering the present SCI.C as the trap free limit, Child's Law can be applied. ${ }^{15.16}$ which states;

$$
J=\frac{9}{8} \mu \epsilon \varepsilon_{10} \frac{V^{2}}{d^{3}}
$$

where $J$ is the current density, $\mu$ is the $\mathrm{SCLC}$ mobility of holes, (a)

(b)
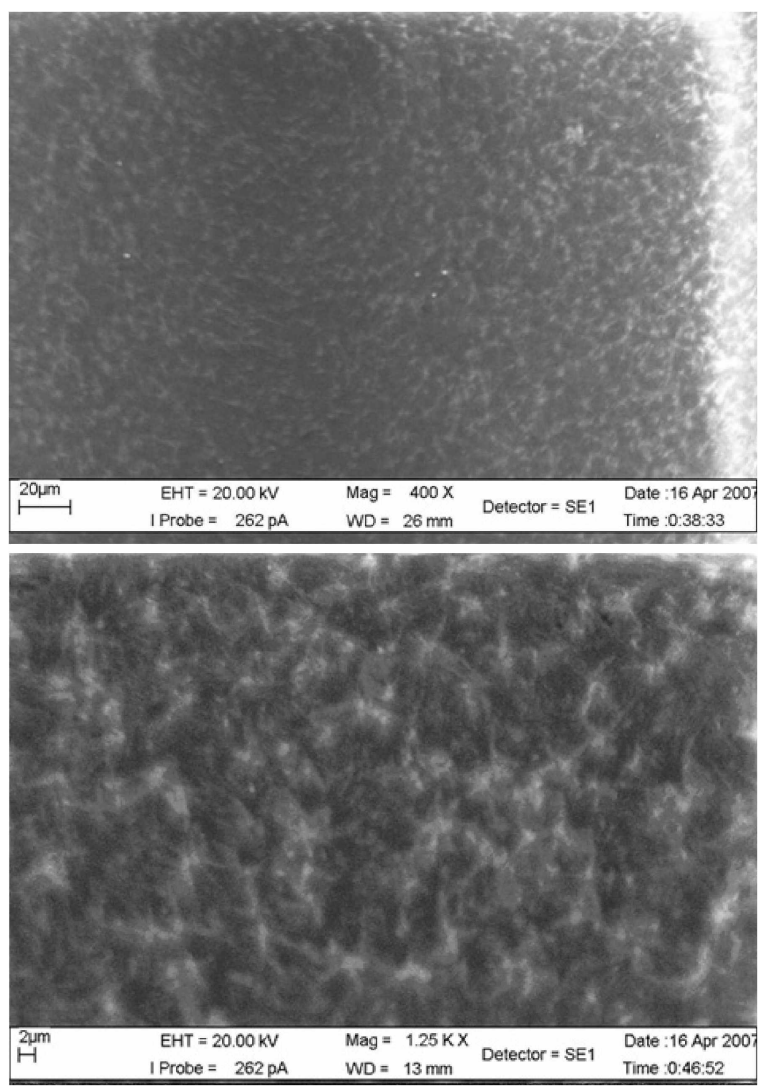

Figure 7. SEM image of the thermally grown film over ITO substrate [Resolution (a) 20 ․ㅏ (b) $2 \mu \mathrm{m}$ ].

$\varepsilon$ is the dielectric constant, $\varepsilon_{0}$ is the permittivity in a vacuum, $V$ is the applied voltage and $d$ is the film thickness.

Using the above J-V relationship, SCI.C mobility was calculated to be of the order of $10^{-6} \mathrm{~cm}^{2} / \mathrm{V}$-s (Fig. 6), which is in accordance with earlier reported values for such types of small molecules. ${ }^{17}$ The SEM images (Fig. 7) of the film grown over ITO substrate shows a reasonably uniform growth of the material with grain size of more than I unn. The large grain size has been obtained due to reinforcement of $\pi-\pi$ stacking of the biphenyl rings with intemolecular hydrogen bonding interactions. In this highly dense and granular crop of dehydrodivanillin, the grains are closely packed and uniformly distributed. Because of this regularity of grains in solid state, the internolecular carrier transport by hopping is highly efficient and losses of carrier at grain boundaries by phonon scattering are minimum. This feature has been translated into appreciable electrooptical characteristics.

Synthesis \& Characterization. Dehydrodivanillin was synthesized as described in the ref. 9. yield: $87.8 \%$; m.p.: 306 $307^{\circ} \mathrm{C}$ ( (Lit". $305^{\circ} \mathrm{C}$ ); IR (KBr): 3247.46 (hydroxyl group), 1674.06 (carbonyl), $1587.31,1504.97$ (aromatic ring) $\mathrm{cm}^{-1}$; ' $\mathrm{H}-$ NMR (DMSO- $\left.d_{6}\right): \delta 9.8(2 \mathrm{H}, \mathrm{s},-\mathrm{CHO}), 7.4\left(4 \mathrm{H}, \mathrm{d}, \mathrm{Amm}-\mathrm{H}_{,}, J_{\mathrm{m}}=\right.$ $3 \mathrm{~Hz}), 3.9\left(6 \mathrm{H}_{*} \mathrm{~s}, 2 \times \mathrm{OCH}_{3}\right) ;{ }^{13} \mathrm{C}-\mathrm{NMR}\left(\mathrm{DMSO}-d_{6}\right) ; 855.95$ $\left(\mathrm{OCH}_{3}\right), 109.20(\mathrm{C} 4), 124.63(\mathrm{Cl}), 127.6 \mathrm{l}(\mathrm{C} 3), \mathrm{l} 27.97(\mathrm{C} 2)$, 148.20 (C5), 150.66 (C6), 190.95 (CHO); GC-EI-MS (di-TMS derivative $): 445.9(\mathrm{M}+, 48 \%), 431\left(\mathrm{M}^{\prime}-15,100 \%\right)$ calcd. 446.6 . 


\section{Conclusions}

The commercial importance of dehydrodivanillin prompted us use it for as precursor for crosslinkers and polymers. For the complete characterization of molecule we carried out $2 \mathrm{D}-\mathrm{NMR}$ studies. Based on which. ${ }^{13} \mathrm{C}-\mathrm{NMR}$ values for dehydrodivanillin have been reassigned. Conjugation between two aromatic rings and efficient $\pi-\pi$ stacking in the film has led to good film properties that is evident from SEM images and reflected in much better electrical and optical characteristics compared to earlier reports with SCLC mobility as high as $10^{-6} \mathrm{~cm}^{-2} / \mathrm{V}$-s. Delydrodivanillin has shown immense potential to be used for the development of conducting polymers and crosslinkers for polymers. CNTs and biomolecules. in electronic applications

Acknowledgments. We thank The Principal, St. Stephen's College. Delhi for providing facilities. We thank Defence Research Development Organisation (DRDO). Department of Science and Technology (DST). University Grants Commission (UGC). Govt. of India. New Delhi for the grant of research projects. We thank SIF, I.I.Sc., Bangalore and Dr. Russell Hopson. Brown University. U.S.A. for recording the NMR spectra and Dr. Tun-Li Shen for recording the GC-EI-MS spectra. We thank Prof David Cane, Brown University. Providence. RI. U.S.A for assistance received during St. Stephen's CollegeBrown University exchange visit by one of us (SVE).

\section{References}

1. Katahira, R.; Nakatsubo, F. J. Wood. Sci. 2001, +7, 378.

2. Hergert, H. J. Oig. Chem. 1960, 405

3. Ikemoto, T.; Nakatsugawa, H.; Taira, A. Jpn. Kokai. Tokkro. Koho. 1995, JP 93-347851.

4. Egawa, Y.; Hanzan, A.: Sato, N.: Ikemoto, T. Jph Kokai. Tolkro. Koho. 2000, IP 98-259781.

5. Reiss, I.: Gattield, I. L.: Krammer, G.: Clere, A.: Kindel, G. L. S. Patent 0286237,2006

6. Medina, A.; Ferreira, L.; Tadros, S.; Sizenshy, J; Fregeolle, M.; Blakeney, A.; Toukhy, M. Proceedings of SPIE 1996, 448.

7. Blakeney, A. J.: Medina, A. N.; Toukhy, M. A.: Ferreira, L:; Tadros, S. L. S. Patent 5541033, 1996.

8. Yamamoto, H.: Hoshino, T.: Uchiyama, T. Biosci. Biotechnol. Biochem. 1999, 63, 390.

9. Elbs, K.; Lerch, H. J. Prakt. Chent 1916, 93, 1.

10. Poplaskyya, D.: Nelson, T. J. Appl. Phy 2003, $93,341$.

11. Sur, S. S.; Sariciftci, N. S. Organic Photovoltaics: Hechanisnts, Naterials, and Derices: CRC Press: Florida, U. S. A., 2005.

12. Andraud, C.: Brotin, T.: Garcin, C.: Pellé, F.: Coldner, P.: Bigot, B.: Collet, A. J. An. Chem. Soc. 1994, 116, 2094.

13. NMR spectra recorded by us at $300 \mathrm{MHz}$ and $400 \mathrm{MHz}$ in DMSO-d did not show the expected meta coupling.

14. Russell, W. R; Scobbie, L; Chesson, A. Bioorg Med. Chem. $2005,13,2537$.

15. Mott, N. F.; Guney, R. W. In the Electronic Processes in Ionic Cinstals; Clarendon Press: New York, 1948 (Reprinted 1964).

16. Rashmi; Kapoor, A. K.: Kumar, U.: Balakrishnan, V. R.: Basu, P. K. Pramana 2007, 68, 489

17. Yasuda, T.; Yamaguchi, Y; Zou, D. C.; Tsutsui, T. Jpn. J. Appl. Pln: 2002, 11,5626 . 